Revista Iberoamericana, Vol. LXXV, Núm. 226, Enero-Marzo 2009, 95-105

\title{
POESÍA, NACIÓN Y DIFERENCIAS: CINTIO VITIER LEE A VIRGILIO PIÑERA
}

\author{
POR \\ JESÚs JAMBRINA \\ Viterbo University
}

En los párrafos siguientes me interesa analizar la reseña literaria que el crítico Cintio Vitier escribiera sobre Poesía y prosa (1944), la quinta publicación de Virgilio Piñera (1912-1979). La reseña fue dada a conocer en la revista Orígenes en el año 1945 (5 47-50) y con el tiempo devendría punto de partida para cualquier estudio sobre la obra piñeriana. En su nota, Vitier codificó la poética del autor como negativa, en el sentido de que representaba lo que para él era el lado desustanciado de la realidad nacional. A ese tipo de escritura, el crítico la llamó del vacío porque, según él, aludía a “un mundo al que [...] se le ha sustraído el verbo” (Crítica 2 147), o lo que es lo mismo a un mundo sin Dios.

El trabajo que sigue intenta problematizar este criterio en la medida en que, si bien en él Vitier señala aspectos fundamentales para su momento y en cierto sentido válidos todavía hoy en cuanto a algunas de sus referencias históricas, a su vez silencia, o cuando menos descuida, otras zonas del proyecto creador de Virgilio Piñera, las cuales completan el mismo en términos epistemológicos.

Hasta la publicación de la reseña en la revista Orígenes, las relaciones entre Vitier y Piñera habían sido cordiales y ambos habían expresado sus criterios sobre la labor del otro en cartas personales a propósito de sus libros respectivos (Piñera, 2 de diciembre de 1943; Vitier, noviembre de 1943, agosto de 1944). Antes de Poesía y prosa (1944), Piñera había dado a conocer Las furias (Poesía, 1941), El conflicto (Cuento, 1942), La pintura de René Portocarrero (Ensayo, 1942) y La isla en peso (Poesía, 1943). Además había editado la revista Poeta (1942-43), en la cual el propio Vitier publicó poemas y traducciones.

Al momento de escribir su valoración, y éste sería un primer punto a tener en cuenta, Vitier conocía el trabajo piñeriano al detalle y, como se demuestra en su intercambio epistolar, no lo aceptaba como posibilidad dentro de la visión que él, junto a otros miembros del llamado grupo Orígenes, defendía como viable para la cultura cubana en aquellos momentos. Puede afirmarse que, siguiendo su método de estudio con respecto a otros escritores, en cuanto a Piñera "la captación amorosa 
y desinteresada" del centro del poeta (Crítica 2 155), en vez de "un conocimiento íntimo” (156), provocó (y desplegó) una paranoia analítica que le imposibilitó traducir las complejidades expresivas del lenguaje poético de su estudiado. Aquél se le presenta a Vitier como una amenaza al surgimiento de "otros imperios paradójicamente sombríos de posibilidades y húmedos aún de noche original” (148), en clara referencia, podría decirse, a los libros Enemigo rumor, de José Lezama Lima (1941) y Saúl sobre la espada, de Gastón Baquero (1942).

Como su título lo indica, Poesía y prosa (1944) está compuesto por sesenta y seis páginas de poemas (8) y relatos (14), la mayoría de estos últimos muy cortos. Si por una parte,la obvia calidad de los textos obliga a Vitier a emitir un criterio positivo sobre ellos desde el punto de vista formal, por otra su opinión busca neutralizar las zonas desestabilizadoras de la propuesta piñeriana, o lo que es lo mismo, Vitier concentra su mirada en el significado negativo de dicha propuesta, intentando suplantarlo con una visión ejemplarizante que se yuxtapone a aquella que el propio Piñera ofrece como respuesta a las complejas preguntas que emergen de su sensibilidad. Como se ha recordado al inicio, fue en esta nota donde Vitier estableció la opinión sobre la obra piñeriana como un testimonio del vacío existencial del país en aquel momento:

\footnotetext{
Claro que se trata de una voz que ha de salir, para que alguien la escuche por lo menos como señal confusa, de lo vano y cóncavo de una máscara, de un resonador, no de un pecho desahogado y libre; pero esa oquedad y falsía responde sobre todo a la condición y exigencias de lo que debe testificar, que no es un paisaje, ni una soledad, ni siquiera un abismo, sino, rigurosamente, un vacío.

Llamamos aquí vacío al reverso humano de la nada, pues en ésta palpita siempre una significación divina, ya sea la nada como pecado (no ser del mal) o la nada como anegamiento del místico en su arrebato de plenitud, o incluso la nada mágica de la extrañeza y angustia del mundo, en que a veces residimos y que podemos saber a qué alude. Pero sin duda, lo sabemos porque su íntima forma interrogante, alude. Lo propio del vacío, sin embargo, es no aludir a nada, sino, en última instancia, a la nada misma, pero entendida aquí no como Pecado, ni como Inefable, ni como Ser Que No Es [sic], sino en cuanto rigurosa categorización del vacío de un mundo en que las cosas y las criaturas están y nada más sobre una superficie siniestra de trivialidad, armando el espantoso y vacuo disparate que lo absorbe todo. (Crítica 2 146)
}

Las preguntas que surgen inmediatamente después de leer estos párrafos se pueden resumir en las siguientes: ¿Es la interpretación de Cintio Vitier fiel a los textos a los que se refiere? ¿No testifica Piñera un paisaje, una soledad o un abismo?¿Qué entiende el crítico por estos sustantivos? ¿Tiene que haber una contradicción entre estos últimos y su representación, así como la de un vacío? Por 
sus opiniones sobre La isla en peso (1943), sabemos que el crítico no acepta como real la descripción de la nación que este poema propone. ¿Podría él ver entonces los paisajes, las soledades y los abismos en los poemas y los relatos de Piñera? Para responder estas preguntas, no nos queda más remedio que volver a los textos a los que Cintio Vitier atribuye connotaciones vacuas.

\section{COMPROMISO Y SOLIDARIDAD}

La primera contradicción es que el poema inaugural del libro, "Vida de Flora", será el mismo y único poema de Piñera que, años más tarde, el crítico escogerá para oponer al resto de la obra poética del autor, enarbolándolo como la sensibilidad positiva que este último pudo haber desarrollado. "Vida de Flora”, cuya posición al inicio del volumen nos invita a entenderlo como la poética general del mismo, expone ciertamente una ética que será reconocible en el resto de este libro, pero también en el resto de la obra literaria de Piñera. Así mismo, evidencia una de las propiedades metamórficas de su poesía: la transformación de los objetos en sujetos, las cosas inanimadas en animadas. ${ }^{1}$

Si en La isla en peso la geografía nacional aparece descrita tanto en sus elementos naturales como en los humanos -el agua, el sol, los árboles, el deseo sexual, la historia, el amor, entre otros-, así como en la profunda interrelación en la que estos elementos existen en la realidad, en este primer poema del libro de 1944 la isla aparece personificada en el nombre de una mujer, Flora, cuya etimología e historia (diosa de las flores para los romanos) remite, indefectiblemente, al protagonismo del mundo natural en la poesía de Piñera, aunque siempre desde una perspectiva dinámica. "Vida de Flora" igualmente narra la peculiaridad (y soledad) de esta mujer, cuya condición física -elevada a situación grotesca-no le permite integrarse completamente al espacio social que le rodea:

Oye, Flora: tus pies no caben en el río que te ha de conducir a la nada,

al país en que no hay grandes pies ni pequeñas manos ni ahorcados.

Tú querías que tocaran el tambor para que las aves bajaran, las aves cantando entre tus dedos mientras el tambor repicaba. Un aire feroz ondulando por la rigidez de tus plantas, todo eso que tú pensabas cuando la plancha te doblegaba. (La isla 46)

\footnotetext{
1 En más de una ocasión, Piñera se refirió a cómo sería necesario pasar de una posición pasiva a una activa mediante el uso del lenguaje (“El país del arte”, 1947) y también del cuerpo ("Los dos cuerpos”, 1974).
} 
El peso ontológico de este texto supera "la ternura y sobrecogimiento" con que Vitier lo relaciona en Lo cubano en la poesía. Tampoco, como el crítico afirma, es sólo un "descenso a las humildes realidades" (407); todo lo contrario: más allá de ambas experiencias y como culminación de ellas el hablante del poema, al tiempo que revela, completa gozosamente el vacío que ha descubierto y, lejos de bordearlo elípticamente, lo enfrenta con el poder de su compromiso y solidaridad: "Flora te voy a acompañar hasta tu última morada./ Tú tenías grandes pies y un tacón jorobado" (La isla 46).

"Vida de Flora" es, obviamente, la mujer, pero es también una metáfora de todos los sujetos desplazados del centro de atención discursiva a causa de una anormalidad más o menos evidente, ya sea esta económica, física, ambas a la vez, o incluso religiosa y, por supuesto, sexual y racial. Y, en este sentido, es una visión nacional en la medida en que, como sugiere la serie isla, Flora, nación, refiere a una situación poética en la que el hablante se convierte en agente de cambio a través del uso del lenguaje para fijar un acto civil preciso. Véase, por ejemplo, el poema "Isla", escrito en 1979 (La isla 214), en el cual el hablante se transforma lentamente, él mismo, en una isla. Este no era un tipo de recurso poético o posición ética inédita en la labor de Piñera cuando Vitier escribe su nota. Al final de La isla en peso, el sujeto apela directamente a la responsabilidad social en un contexto concreto, fusionándose con él: "siempre más abajo, hasta saber el peso de su isla;/ el peso de una isla en el amor de un pueblo” (La isla 44).

A "Vida deFlora" siguen ocho poemas en los cuales, con más o menos intensidad, conviven simultáneamente las representaciones del vacío y el (re)nacimiento de los sujetos y las cosas del mundo. No se trata de anular en mi lectura la vocación destructiva que Vitier menciona en la carta a Piñera y que éste mismo declara más de una vez en su obra, sino de tratar de entender si a la poesía del autor puede atribuírsele sólo el lado negativo que históricamente, de manera ejemplarizante, se le ha reconocido.

La condición híbrida de la estética piñeriana no debe ser rastreada sólo en cuanto a la diversidad de géneros literarios que este autor practicó; es una condición que se complementa con los giros metamórficos (formales y éticos) que una y otra vez encontramos en su escritura, sea ésta del género literario que sea. La atmósfera de contrapunteo discursivo habitual en los años cuarenta en Cuba permea el estilo y los temas con los que los poetas, escritores y sociólogos trabajan, no sólo Virgilio Piñera. El contrapunteo era (es) un método de representación común tanto, por ejemplo, a los discursos literarios como a las expresiones musicales clásicas y populares. Su uso, puede afirmarse, era un dogma estético que se reproducía compulsivamente en las obras antropológicas y de ficción de Fernando Ortiz y Alejo Carpentier, 
respectivamente, así como en las llamadas controversias campesinas, tradicionales en el ambiente rural cubano. ${ }^{2}$

LAS DOS NADAS

La sección del libro dedicada a los versos termina con un texto titulado "Poema para la poesía”. Es uno de los varios que el autor escribió a lo largo de su carrera donde piensa las posibilidades de este género. Piñera siempre le atribuyó a la poesía un valor propio, es decir la vio como un reino autónomo, cuya función extraliteraria, si alguna le correspondía, estaba inserta dentro de sus propias necesidades de comunicación: "Yo no postulo-escribió a comienzo de los sesenta-el hecho poético desde lo social y lo político, desde lo pretendidamente americano, sino desde la poesía en sí misma, por sí misma y para sí misma” (Lunes “Votos y vates” 12).

No quiere esto decir que el autor tuviese una actitud evasiva de lo social, todo lo contrario: reconocía en la actividad artístico-literaria, como lo expuso en su ensayo de 1947 “El país del arte” (Poesía y crítica 135-40), una práctica social centrada en la representación fiel y radical de los conflictos humanos. Y desde el punto de vista institucional, como un sistema que justificara la existencia misma de los escritores y artistas, promoviendo, reconociendo y evaluando su labor creadora (“Cuba y la literatura” 51-55). Luego, los criterios piñerianos sobre la literatura, y la poesía en particular, hay que entenderlos en la frontera entre lo estrictamente literario -entiéndase preocupación por las formas discursivas y la tradición- y lo específicamente ideológico -desde dónde y para quién se escribe-

En el "Poema para la poesía”, Piñera reconstruye su relación con la diversidad de discursos de su tiempo, específicamente con las tendencias culteranas, a las cuales encuentra agotadas en su insistencia en lo clásico y lo tradicional. Después de declarar en las primeras estrofas que no quiere entrar en el ensimismamiento del sueño ( $L a$ isla 59) y de avanzar resistiendo los embates de éste, el hablante invoca la posibilidad de un camino diferente y define la situación de esta manera:

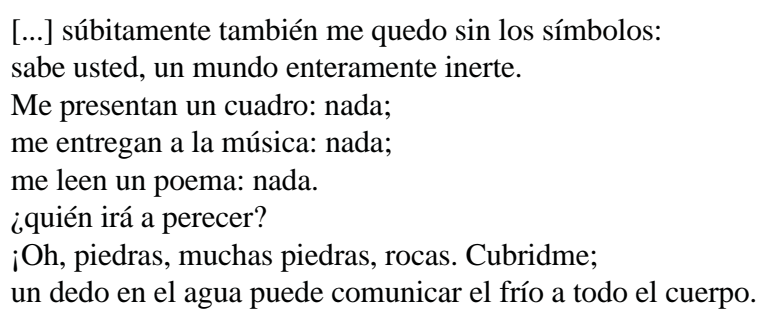

2 Para una reseña del término contrapunteo, ver la introducción de Enrico Mario Santí al Contrapunteo cubano del tabaco y el azúcar (Ortiz 26-29). 


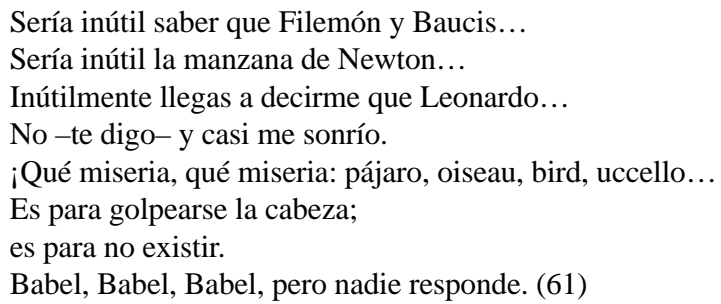

A diferencia del concepto de la nada que parece priorizar Vitier, asociándolo al vacío o a ausencia del Verbo (Poesía y prosa 48), lo que Piñera llama nada por defecto, en la cita anterior encontramos la nada por abundancia o, como le llama Piñera, nada por exceso. Aunque desde puntos extremos, y bajo condiciones de producción distintas, las dos nadas comparten el mismo resultado: ingravidez, no acto, infecundidad, soñolencia.

En su ensayo "Cuba y la literatura" (Ciclón 51-55), Piñera reflexiona lo siguiente:

El sentimiento de la Nada por exceso es menos nocivo que el sentimiento de la Nada por defecto: llegar a la nada a través de la Cultura, de la Tradición, de la abundancia, del choque de las pasiones, etc. supone una postura vital puesto que la gran mancha dejada por tales actos vitales es indeleble. Es así; [sic] que podría decirse de estos agentes que ellos son el "activo" de la Nada. Pero esa Nada, surgida de ella misma, tan física como el nadasol que calentaba a nuestro pueblo de entonces, como las nadacasas, el nadaruido, la nadahistoria... nos llevaba ineluctablemente hacia la morfología de la vaca o del lagarto. A esto se le llama el “pasivo” de la Nada, y al cual no corresponde “activo” alguno. (53)

Es decir, para Piñera, la acumulación histórica, entendida como Tradición, aun a través de la inercia, le permite al sujeto que la vive actuar en la realidad, hacerse visible, real en tanto reproduce una situación heredada o aprendida disciplinadamente. En el otro extremo, allí donde no se lleva a cabo ninguna creación radical persiste sin embargo la naturaleza física, lo que él llama metafóricamente "la morfología de la vaca o del lagarto", refiriéndose irónicamente a un tipo de imaginario cultural que prefiere recrear la historia mediante la conformación de un bestiario o, lo que es igual, la descripción elemental de seres y objetos de naturaleza onírica que sustituyen las necesidades y los conflictos del sujeto. En ambos casos, el individuo, según Piñera, no participa plenamente de su entorno, sino que se asimila a él o se integra sin transformarlo para su beneficio.

El hablante del "Poema para la poesía”, dueño, por otra parte, de un "amoroso deseo" (La isla 59) en el sentido solidario de "Vida de Flora", no obstante, descubre 
que lo que el discurso a su alrededor le ofrece no soluciona sus ansias de trascendencia. Se trata de una voz que, en oposición a la descrita por Vitier, también posee un impulso teleológico, cuya necesidad es manifiestada por dicha voz, pero cuya vía de realización es (descansa en) la escritura poética misma:

No queda una sola fotografía del Partenón ni tampoco del Vaticano.

No queda nada sino el amor.

¡Oh, perro, perro mío, aúlla; ofréceme un poema de aullidos. ${ }^{3}$

Concédeme esta gracia extrema, tú mismo lo leerás

mientras yo quemo los demás poemas. (62)

Así, tenemos que el mundo destruido queda restaurado mediante un uso primigenio de las palabras, ofreciendo una dimensión oscura y misteriosa de las mismas. El hablante de Piñera posee una conciencia radical de este efecto poético, y practicándolo se aleja de cualquier manía expresiva que lo haga reproducir la nada por exceso a la que ciertamente aquí alude. El vacío al que se refiere, en tanto saturado de tradición, abarca incluso las definiciones que Cintio Vitier diseñó para su poesía y que, como hemos dicho, han llegado hasta hoy, en parte ayudadas por el propio Piñera, cuya obra poética sufrió irregularidades en la circulación, que la hicieron desaparecer del campo literario por veinticinco años, hasta la publicación de su antología La vida tal cual (1969).

Allí donde Cintio Vitier (y Orígenes en general) desarrollan una interpretación fetichista de la cultura clásica occidental, lo cual invoca una presencia (metafísica) del Espíritu, Piñera, identificado con el lado crítico de la misma tradición, ve en ella un recorrido mortal hacia la Nada. Refiriéndose al tipo de escritor esteticista y enciclopédico de su tiempo -en lo que se reconoce una crítica tanto a Lezama como a Borges-, en el mismo artículo "Cuba y la literatura” Piñera plantea el dilema:

Se daba así en una literatura joven [habla de la cubana] el mismo fenómeno que observamos en las viejas literaturas: me refiero a los retóricos de la decadencia. Cualquiera que echase una ojeada a tales producciones se sorprendería del afán de decadencia de un pueblo joven en términos de alta cultura. ¿Es que ya habíamos tenido nuestro Siglo de Oro como para darnos el lujo del bizantinismo? Recuerdo

3 No asocio el símbolo del perro en la poesía de Piñera con ningún imaginario de subordinación, interpretación tan común en las culturas populares modernas, sino con la tradición cínica que tiene en Diógenes de Sinope (400-325 D.C.) uno de sus mayores representantes. La etimología de la palabra cinismo se remonta al griego, idioma en el que significa perro. A los cínicos se les llamó perros porque, entre otras cosas, no tenían vergüenza en llamar las cosas por sus nombres, especialmente todo lo relativo a los asuntos públicos. Sobre Diógenes, el cínico (o el perro), se cuenta que una mañana salió a la calle con una lámpara alumbrada en busca de un ser humano, sugiriendo que estos últimos habían desaparecido a causa de la corrupción política. 
el caso de $\mathrm{X}$, uno de esos escritores que al pasar junto a usted causan el mismo efecto de una tremenda corriente de aire en el rostro, a tal punto que le brotaban las citas por todos los poros... Ante su obra uno se preguntaba [...] ¿Para quién escribe X? Pues escribe para un grupo de amigos que, en justa reciprocidad, escriben para X [...] Es decir, que la obra de X, aparte de sus innegables virtudes formales -elegancia, fluidez, frases diamantinas- no se religa en absoluto con ningún tipo de realidad; en ningún momento comprobamos que la ornamentación esté en sus escritos en función de algo más que mero adorno.

No insisto más, pero dejo a la consideración del lector esta pregunta: si a pesar de no ser el esteticismo de dichos escritores el fondo último de sus obras, nos resulta el mismo, gratuito, y comprobamos que, precisamente, por su misma artificiosidad, es un lastre, ¿qué menos entonces si leyendo un manuscrito de X, que experimentar una desagradable sorpresa al comprobar que masticamos el vacío absoluto? (54)

Desde esta perspectiva, en la que como es obvio resuenan a la inversa los argumentos de Vitier, Piñera reclama una (re)composición de las formas que permita reinterpretar el espacio nacional desde una posición democrática, donde la creación abarque, como lo afirmaba en 1943 en una carta al propio Vitier, no sólo "la belleza conocida”, sino "la belleza desconocida” (2 de diciembre de 1942, inédita).

\section{(CONTRA)APROPIACIÓN MÍSTICA}

Pero en 1945 Cintio Vitier, frente a la inestabilidad de una propuesta como la de Piñera, no sólo trató de ceñirla a normas interpretativas esencialistas, sino que deliberadamente se (contra)apropió de algunos de sus recursos expresivos, desorientando a la comunidad letrada del momento acerca de un poeta cuya “vocación de cáncer" (noviembre de 1943, 88) le servía para remover los cimientos aristocráticos de la cultura, pero que junto a ella, enlazada en su centro, igualmente ofreció un "amoroso deseo" de reconstrucción a través de la poesía entendida en el sentido antiguo de creación (poesis). Vitier (des)califica este último deseo, llamándolo cursi:

No hay aquí-en la escritura de Piñera-absolutamente, para nosotros, desesperación ni caos. Por el contrario, lo que hay es un mundo al que, dicho sea con valentía y tosquedad, se ha sustraído el verbo. Esto explica la imposibilidad tanto de la esperanza, como de la desesperación, de la creación como del caos; y la profunda frecuencia de lo cursi. (Crítica 2 147) 
Para el crítico, quien siguiendo al escritor español Ramón Gómez de la Serna afirma que "lo cursi es todo sentimiento no compartido" (48), ${ }^{4}$ no valen ni la explícita solidaridad del poeta con "las humildes realidades" en "Vida de Flora" (Lo cubano 408), ni la defensa del poema como refugio de Amor (La isla 62), lo cual, de hecho, apela también a cierta teleología, a cierto tipo de espiritualidad humanista.

Y es que, y éste sería el desacuerdo raigal entre Virgilio Piñera y la mayoría de los miembros de Orígenes, al autor de Poesía y prosa no le interesaba lo que podemos llamar el contenido hegemónico del conocimiento que el nacionalismo de Cintio Vitier promulga; en él vio un instrumento perverso que, lejos de liberar a los seres humanos, los esclaviza a las costumbres del poder, cuya estructura vertical necesita de férreos valores que reproduzcan, objetiva y subjetivamente, las jerarquías ideológicas que le permitan sobrevivir al flujo emancipador de la naturaleza humana. La marcha mítica de Occidente, como lo había demostrado la historia europea en la primera mitad del siglo xx, no tenía por qué ser seguida disciplinadamente, pues obstaculizaba, y este sería el momento utópico de Piñera, la llegada completa y necesaria de la modernidad a la periferia latinoamericana. ${ }^{5}$

Amodo de conclusiones podemos decir que, tomando como punto de partida el concepto de vacío, Vitier, en su reseña sobre Poesía y prosa, elabora un argumento que omite las complejidades que representa la obra de Piñera. Si bien es cierto que los poemas de este autor en un sentido defienden una visión desierta de la realidad cubana, en otro y frente a este hecho el hablante de sus textos también ofrece una compensación que permite la reconstrucción de esa misma realidad. El argumento de Vitier es eficaz, sin embargo, porque atribuye ese vacío a la condición neocolonial en la que vivía el país en la década de los cuarenta, un referente que

4 En rigor, Vitier desorienta al lector con esta cita, pues, en su conocido ensayo, el escritor español hace una distinción entre "lo cursi deleznable y sensibilero y lo cursi perpetuizable y sensible o sensitivo" (21), procediendo entonces a explicar uno y otro y ubicando al segundo en lo mejor de la tradición hispana con raíces en el período barroco. Por otro lado, la frase que usa Vitier no es de De la Serna, sino de una ex novia de éste que se la escribe como parte de la explicación de sus sentimientos. En el texto, la frase está en cursivas para subrayar que es de otra persona, no del autor (29). Por otra parte, la invocación de lo cursi en el ensayo de Gómez de la Serna es para defenderlo, no para atacarlo, lo cual da pie para pensar cierta reincidencia de Vitier en (contra)apropiarse de conceptos que, en su fuente original, tenían significados algo diferentes a los que les da el crítico.

5 Si por una parte no cabe duda de la vocación nacionalista del autor, por otra y como parte de su deseo de cambio social se pueden rastrear algunos conceptos en él que verifican un alineamiento ideológico con las democracias históricas europeas, en el sentido de que éstas habían reconocido en la cultura una fuente de prestigio nacional, desarrollando un sistema institucional que le daba al escritor un amplio reconocimiento público. Este tipo de perspectiva fue considerada por la revolución liberal y diversionista, llevando a la clausura del conocido semanario Lunes de Revolución, del cual saldrían varios de los escritores cubanos más conocidos de los últimos cincuenta años: Guillermo Cabrera Infante, Severo Sarduy y Antón Arrufat, entre otros. 
la ciudad letrada en su conjunto, por encima de las diferencias estéticas o de otro tipo, compartía perfectamente.

Luego, al concepto de vacío y al de negatividad que éste implica se asocia la idea de que, terminadas las condiciones que los provocaban, no habría espacio para ese tipo de representación, quedando el campo literario cubierto entonces por las visiones afirmativas de otros “imperios poéticos” (Crítica 2 148), como el mismo Vitier llama a las estéticas de Lezama Lima y Gastón Baquero y quizá a la suya misma: en 1944, él publica Extrañeza de estar. Al final, en el devenir poético cubano, según se puede deducir de las opiniones de este crítico, Virgilio Piñera sería un autor prescindible.

La fosforescencia del argumento vitieriano no logra esconder su superficialidad, sobre todo si, como intentamos, se vuelve al libro en cuestión y se lee en función de sus propuestas epistemológicas. Junto a la expresión de un vacío, eso que el propio Piñera llamó, en carta a Lezama, su "teoría de las destrucciones" (Fascinación 273), donde se prioriza los actos ambiguos, indecisos a los que el sujeto hablante se enfrenta diariamente, existe un impulso redentor, si se quiere, un "amoroso deseo" que adquiere la forma de la solidaridad en "Vida de Flora” (La isla 45-46) y en "Poema para la poesía” (59-62).

Un recorrido por la sesión de versos del libro verifica una poética donde uno y otro gestos discursivos se hacen visibles contrapuntísticamente, igual que sucede, por ejemplo, en La isla en peso. Según Piñera, vivimos en un mundo donde las realidades se superponen las unas a las otras y el sujeto emerge de ese contraste, de ese entrar y salir de lo privado y de lo público, lo abstracto y lo concreto, lo real y lo simbólico, el presente y el pasado, la verdad y la mentira.

En un segundo momento, vemos cómo la idea de la nada a la que el poeta recurre constantemente en los textos de este libro posee una argumentación ambivalente. Vitier, citando un par de versos de "Vida del pintor" (Poesía y prosa 8) y "Poema para la poesía" (21), destaca el influjo anodino de lo que Piñera llama la nada por defecto, pero reformula en términos místicos lo que igualmente Piñera define como la nada por exceso (“Cuba y la literatura” 53). O lo que es lo mismo, el crítico (contra)asimila en su propia conformación teórica un concepto que es vital a la comprensión equilibrada de la poética piñeriana. No es que a esta última le interese sólo representar las metamorfosis de la nada por defecto, sino también las articulaciones de la nada por exceso, la cual, como vimos, inmoviliza al sujeto mediante una acumulación fetichista del saber. 


\section{BIBLIOGRAFÍA}

Gómez de la Serna, Ramón. Ensayo sobre lo cursi/Escaleras, drama en tres actos. Santiago de Chile: Cruz del Sur, 1963.

Lezama Lima, José. Fascinación de la memoria. Textos inéditos de José Lezama Lima. La Habana: Editorial Letras Cubanas, 1993.

Piñera, Virgilio. Poesía y prosa. La Habana: Edición de Autor, 1944.

Poesía y crítica (Ant., prólogo de Antón Arrufat). México: Consejo Nacional para la Cultura y las Artes, 1994.

“Carta a Cintio Vitier” (2 de diciembre de 1943). Archivos privados de la familia Ibáñez Gómez, Calzada de Managua \# 65, La Habana.

9.

“Votos y vates”. Lunes de Revolución (La Habana, 15 de febrero de 1960):

“Cada cosa en su lugar”. Lunes de Revolución (14 de diciembre de 1959):

11-12.

“Cuba y la literatura”. Ciclón (La Habana, 1956): 51-55.

Vitier, Cintio. “Virgilio Piñera. Poesía y prosa. La Habana, 1944”. La Habana: revista Orígenes 5 (1945): 47-50.

“Carta a Virgilio Piñera”. 7 de diciembre de 1942. Vitral (Pinar del Río, 1997): 88.

“Carta a Virgilio Piñera”. Noviembre de 1943. Vitral (Pinar del Río, 1997): 87-88.

“Carta a Virgilio Piñera” (21 de agosto de 1944). Archivos privados de la familia Ibáñez Gómez, Calzada de Managua \# 65, La Habana.

Lo cubano en la poesía. Villa Clara, Cuba: Universidad Central de Las Villas, 1958.

Crítica 2. La Habana: Editorial Letras Cubanas, 2001. 